University of Nebraska - Lincoln

DigitalCommons@University of Nebraska - Lincoln

U.S. National Park Service Publications and

Papers

National Park Service

$2-18-2020$

\title{
Beryllium-7 Elucidate Sediment Dynamics of the Branford River Estuary, Connecticut, USA
}

\author{
Gaboury Benoit \\ Yale Environment School, gabouryb@gmail.com \\ Matthew Hirschbeck \\ National Park Service - Intermountain Region \\ Beth Bisson \\ University of Maine
}

Follow this and additional works at: https://digitalcommons.unl.edu/natlpark

Part of the Environmental Education Commons, Environmental Policy Commons, Environmental Studies Commons, Fire Science and Firefighting Commons, Leisure Studies Commons, Natural Resource Economics Commons, Natural Resources Management and Policy Commons, Nature and Society Relations Commons, Other Environmental Sciences Commons, Physical and Environmental Geography Commons, Public Administration Commons, and the Recreation, Parks and Tourism Administration Commons

Benoit, Gaboury; Hirschbeck, Matthew; and Bisson, Beth, "Beryllium-7 Elucidate Sediment Dynamics of the Branford River Estuary, Connecticut, USA" (2020). U.S. National Park Service Publications and Papers. 195.

https://digitalcommons.unl.edu/natlpark/195

This Article is brought to you for free and open access by the National Park Service at DigitalCommons@University of Nebraska - Lincoln. It has been accepted for inclusion in U.S. National Park Service Publications and Papers by an authorized administrator of DigitalCommons@University of Nebraska - Lincoln. 


\title{
Beryllium-7 Elucidate Sediment Dynamics of the Branford River Estuary, Connecticut, USA
}

\author{
Gaboury Benoit ${ }^{1}$ (D) $\cdot$ Matthew Hirschbeck ${ }^{2} \cdot$ Beth Bisson $^{3}$
}

Received: 21 June 2019 /Revised: 19 November 2019 / Accepted: 30 January 2020 / Published online: 18 February 2020

(C) Coastal and Estuarine Research Federation 2020

U.S. government works are not subject to copyright.

\begin{abstract}
Berrylium-7 elucidates sediment dynamics (i.e., sources, sinks, deposition, and resuspension) in a Connecticut estuary. Average annual atmospheric deposition of ${ }^{7} \mathrm{Be}$ is $290 \mathrm{mBq} \mathrm{cm}^{-2}$ year $^{-1}$. Sediment samples from 43 locations within the estuary show that ${ }^{7} \mathrm{Be}$ deposition is spatially complex, but were statistically indistinguishable a year apart. Weekly time series of sediments indicate that levels are nearly constant on this shorter time scale once radioactive decay is taken into account. ${ }^{7}$ Be levels in sediments are a balance between steady losses through radioactive decay and periodic pulse inputs following rainstorms. The water column was measured intensively during three rain events, showing that ${ }^{7} \mathrm{Be}$ is removed rapidly from the water column, with a rate constant averaging $1.00 \pm 0.12 \mathrm{day}^{-1}$. A mass balance shows that ${ }^{7} \mathrm{Be}$ is supplied about equally by direct precipitation onto the estuary's surface and inflow from the watershed. Losses from the water column are split between net sedimentation (43\%) and tidal flushing (57\%). Variations in sedimentary ${ }^{7} \mathrm{Be}$ levels at very short (meters) and longer (km) distances, and changes at time scales from hours to years, indicate that a large number of samples are required to capture all the variability in these highly dynamic systems. The current study differs from previous research in that a large number of measurements were conducted on a smaller system, and a full mass balance was developed.
\end{abstract}

Keywords Estuary $\cdot$ Beryllium-7 $\cdot$ Mass balance $\cdot$ Pollution $\cdot$ Scavenging $\cdot$ Rivers $\cdot$ Watershed $\cdot$ Sediments $\cdot$ Deposition . Resuspension

\section{Introduction}

The Connecticut shoreline is marked by numerous drowned stream valleys that now act as estuaries. Sediment behavior in these estuaries is quite complicated. Sources include both upland watersheds and Long Island Sound, and lateral inputs may be important in some cases. In the estuary, sediment can go through cycles of deposition and resuspension followed by either export or redeposition. The long-term pattern seems to be burial at a rate close to relative sea level rise (Benoit et al. 1999; Rozan and Benoit 2001) so that the

Communicated by David Reide Corbett

Gaboury Benoit

gabouryb@gmail.com

1 Yale Environment School, 195 Prospect Street, New Haven, CT 06511, USA

2 National Park Service - Intermountain Region, 12795 W Alameda Pkwy, Lakewood, CO 80228, USA

3 Maine Sea Grant College Program, University of Maine, 5741 Libby Hall, Orono, ME 04469, USA estuaries are close to steady state in terms of their bathymetry. Humans interfere with this pattern in many ways, perhaps most dramatically not only through periodic dredging to maintain navigation channels, but also by changing land use in upstream watersheds, which can lead to variations in sediment contributions from those sources.

Sediment transport, deposition, resuspension, and burial in estuaries are important for several reasons. The biological, physical, and chemical processes operating in an estuary determine the fate of a number of natural and anthropogenic chemical substances that are delivered to the estuary from the ocean, atmosphere, and land. For example, sewage treatment plants and numerous nonpoint sources are often situated on these systems (Howarth et al. 2002). The biologically rich estuarine environment is important because it provides soft bottom habitat and nurseries for shellfish and finfish (Roman et al. 2000). Many salt marshes are also located here and are strongly influenced by sedimentary processes (Vernberg 1993). Estuaries also provide a number of ecosystem services (Barbier et al. 2011), including providing sheltered anchorages, navigation, contaminant disposal, and recreation, which are affected by sedimentation. Estuarine 
sediments are also the repository for considerable amounts of particle-reactive and hydrophobic contaminants (Kennish 2002).

Short-lived radionuclides can be useful for studying the dynamic behavior of sediments in estuaries. They are often added as discrete pulses during storms and can be followed for days or weeks until the next pulse input starts a new cycle (Dibb and Rice 1989a; Olsen et al. 1986). The relatively short half-lives match the timescale of processes occurring in the estuaries. The known radioactive decay rates can be used to provide age and rate information. In this study, we focused on one such radionuclide, ${ }^{7} \mathrm{Be}$ (53.2 days).

\section{Beryllium-7 as a Sediment Tracer}

${ }^{7} \mathrm{Be}$ is a useful tracer for short-term sediment dynamics in aquatic systems thanks to its short half-life of 53.2 days (Dominik et al. 1987). ${ }^{7} \mathrm{Be}$ is produced in the atmosphere by cosmic ray spallation of nitrogen and oxygen (Feng et al. 1999). Although it is predominantly produced in the stratosphere, the bulk of the ${ }^{7} \mathrm{Be}$ that is delivered to the Earth's surface is generated lower, in the troposphere. This is because the residence time of beryllium in the stratosphere is much longer than the life of the radionuclide (Dutkiewicz and Husain 1985).

Direct atmospheric deposition has been shown to be the dominant source of ${ }^{7} \mathrm{Be}$ in estuarine systems studied to date (Dibb and Rice 1989a; Olsen et al. 1986). Direct atmospheric deposition is responsible for greater than $90 \%$ of the total ${ }^{7} \mathrm{Be}$ inputs into Chesapeake Bay, while the transport of beryllium into or out of the Bay is insignificant by comparison (Dibb and Rice 1989a). The relatively low contribution by watersheds of ${ }^{7} \mathrm{Be}$ to estuaries is a result of beryllium's adsorption to vegetation and soil in the watershed for a period significantly longer than its half-life and the small ratio of watershed to estuarine area (Olsen et al. 1986). When ${ }^{7} \mathrm{Be}$ is first deposited from the atmosphere, it is solubilized then quickly rescavenged by particles (Dibb and Rice 1989a; Olsen et al. 1986). Studies have shown that the distribution coefficient $\left(\mathrm{K}_{\mathrm{d}}\right)$ for ${ }^{7} \mathrm{Be}$ in estuarine and coastal waters is relatively large (approximately $10^{5}$, Baskaran and Santschi 1993; Dibb and Rice 1989b). The residence time of ${ }^{7} \mathrm{Be}$ in Hudson River waters ranges from less than 1 to 13 days, varying seasonally (Feng et al. 1999). Greater than $80 \%$ of the ${ }^{7} \mathrm{Be}$ in Chesapeake Bay is found in the sediments, while less than $20 \%$ of the ${ }^{7} \mathrm{Be}$ is in the water column (Dibb and Rice 1989a) as expected from beryllium's very strong affinity for particles. Also, 74$86 \%$ of the total atmospheric deposition of ${ }^{7} \mathrm{Be}$ during a rainfall became associated with particles within $1 \mathrm{~h}$ in Galveston Bay, TX (Baskaran and Santschi 1993). Aggregation and settling of particles resulted in removal of $70 \%$ of the ${ }^{7} \mathrm{Be}$ from the water column in less than 1 day (Baskaran and Santschi 1993; Fitzgerald et al. 2001).

The objective of the current research was to use radionuclides as tracers to investigate sediment supply, deposition, and net accumulation in a typical Connecticut estuary on time scales ranging from days to many months. While some similar studies have been conducted on larger estuaries and lakes, this project differs in focusing on short-term sediment dynamics in small estuaries. Small, in this case, refers to estuaries that are less than $10 \mathrm{~km}$ in length, have average widths between 100 and $200 \mathrm{~m}$, and with watersheds under $100 \mathrm{~km}^{2}$. The Branford estuary has a narrow natural channel flanked by mud flats in some areas; there are also areas of dredged channels. At least seventeen estuaries in Connecticut are similar (i.e., Byram River, Cos Cob Harbor, Norwalk Harbor, Saugatuck River, Southport Harbor/Mill River, Ash Creek, Gulf Pond, West River, Mill River, Farm River, East River, Hammonasset River, Niantic River, Jordan Cove, Mystic River, Pawcatuck River, and Branford River). Little is known about sediment dynamics in these small estuaries, which are prevalent in the northeastern USA and coasts elsewhere. These small systems can be disproportionally important because they have historically served as locations for urban population development and associated pollution sources. One previous study looked at a small system of similar scale, but it was an inland river rather than an estuary (Jweda et al. 2008)

\section{Research Design}

\section{Sampling Strategy}

Our goal was to quantify ${ }^{7} \mathrm{Be}$ in every important environmental compartment and to evaluate fluxes between them at all significant time scales. We sought to make enough measurements to characterize variability at all relevant temporal and spatial scales. Measurements were conducted on rain, sediments (surficial cores), and estuarine waters to evaluate ${ }^{7} \mathrm{Be}$ variations in time and space and to construct a mass balance for a typical small estuary. The study site, the Branford River estuary is $7.2 \mathrm{~km}$ long to the head of the tides, averages $126 \mathrm{~m}$ wide, and has a watershed area of $63 \mathrm{~km}^{2}$ (Fig. 1). A small dam currently blocks its landward extent, but is at the same location where rising altitude would have halted tidal flow in the past. Rain was collected nearby from the roof of Yale's Environmental Science Center, 21 Sachem St, New Haven, $\mathrm{CT}$, about $10 \mathrm{~km}$ away. Storm event samples of the water column (10 L volume) were collected from a site near the $\mathrm{S}$. Montowese Street bridge, Branford, CT (Fig. 1), approximately every $12 \mathrm{~h}$ (at successive high tides) before, during, and for a few days after three rain events. High tides were selected as an end member that emphasized the role of tidal flushing. This location is roughly midway along the length of the estuary. 


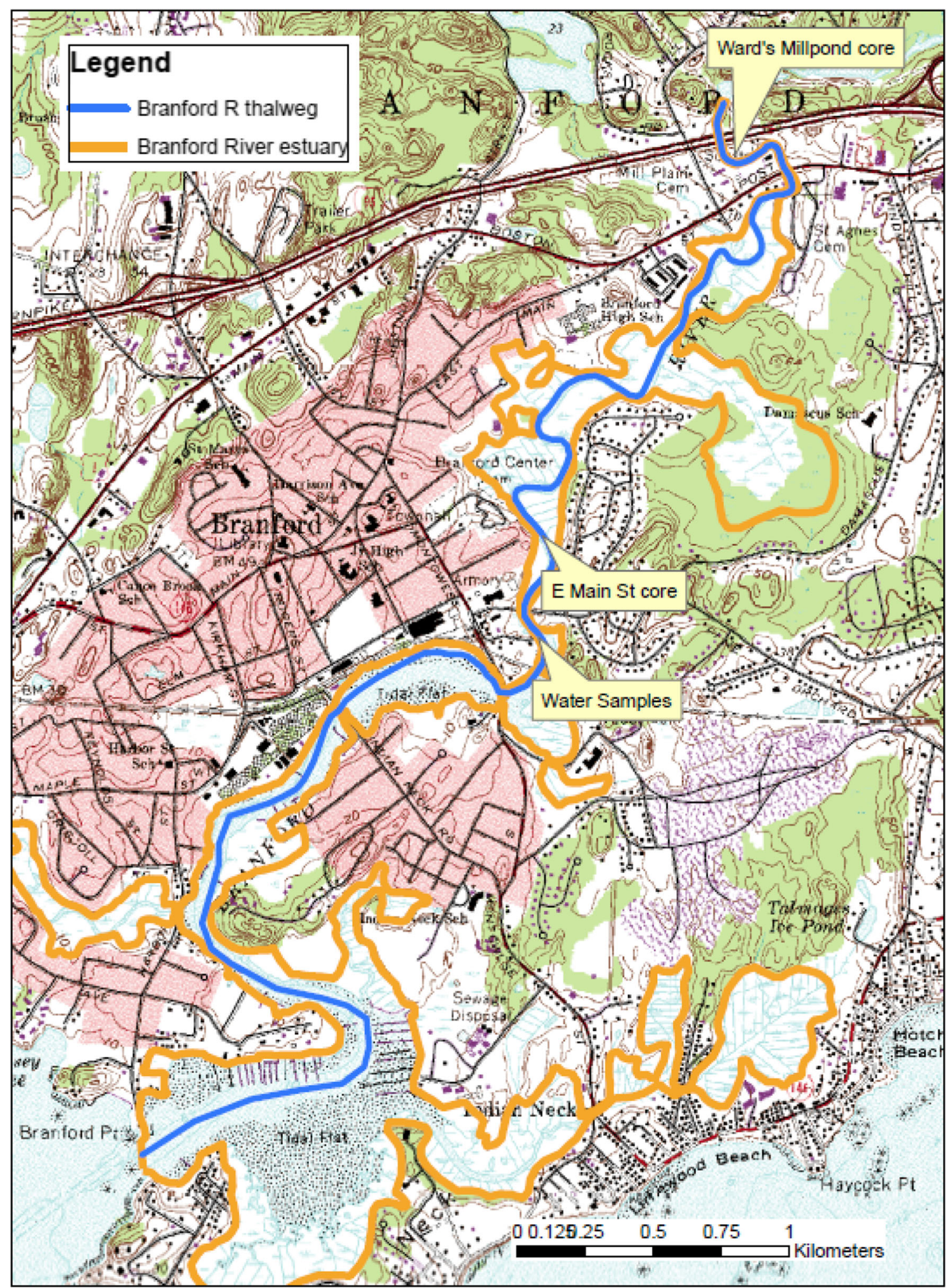

Fig. 1 Map of the Branford River estuary. Surficial sediment samples were collected along the length of the estuary. The orange line delimits the area flooded at the highest tides. Water samples were collected at the

Two rainstorms were measured in the period from November 15 to 19,2002 and a third during the period from July 27 to 30 , location indicated except for those used to characterize input from the watershed, which were collected near the dam. Lower left corner is $41^{\circ}$ $15^{\prime} 25^{\prime \prime} \mathrm{N}, 72^{\circ} 49^{\prime} 35^{\prime \prime} \mathrm{W}$

2004. The watershed contribution of ${ }^{7} \mathrm{Be}$ was assessed via 10 L samples collected where the river enters the estuary (just 
below the dam for Ward's Millpond; Fig. 1). Our extraction method (see below) measures total ${ }^{7} \mathrm{Be}$ (both dissolved and particulate). Sediment samples for ${ }^{7} \mathrm{Be}$ were collected by using a 5 -cm-diameter core liner to subsample the upper $5 \mathrm{~cm}$ of material captured with an Eckman dredge. The liner was inserted into the sediment and capped from below. The entire upper $5 \mathrm{~cm}$ of sediment was extruded into a $100-\mathrm{cm}^{3}$ aluminum can, homogenized, and sealed in the field. This method captured all of the ${ }^{7} \mathrm{Be}$ in the sediment profile as tests of some individual cores revealed none of the radionuclide below $1.5 \mathrm{~cm}$. Subsampling was carried out only if the sediment-water interface looked undisturbed in these collections. For the synoptic spatial distribution study, bottom sediments were collected along the length of the estuary, approximately every $500 \mathrm{~m}$. Two or three stations were collected across the estuary at most of these sites. Two sets of bottom samples were collected (July 23, 2003 and June 11, 2004; Figs. 2 and 3). To evaluate medium-term variation in sediments, a bottom site near $41^{\circ} 16^{\prime} 32^{\prime \prime} \mathrm{N}, 72^{\circ} 48^{\prime} 34^{\prime \prime} \mathrm{W}$ (between Indian Neck Ave and S Montowese St) was re-sampled repeatedly between rainstorms (roughly weekly). In addition, sets of triplicate or quadruplicate samples were taken nearby to evaluate variability over short distances (a few m) at a single location.

To study the effect of storms, samples were taken before, during, and after each rain event according to the schedule shown in Table 1. In order to minimize the effect of diurnal variations of tidal exchange on ${ }^{7} \mathrm{Be}$, samples were taken at the same tidal stage. In this case, all samples were collected within about an hour of high tide in order to ensure that conditions remained relatively constant from day to day. At each time point, a sample core (homogenized, approximately $5 \mathrm{~cm}$ in length and $5.0 \mathrm{~cm}$ in diameter) was taken along with a $10-\mathrm{L}$

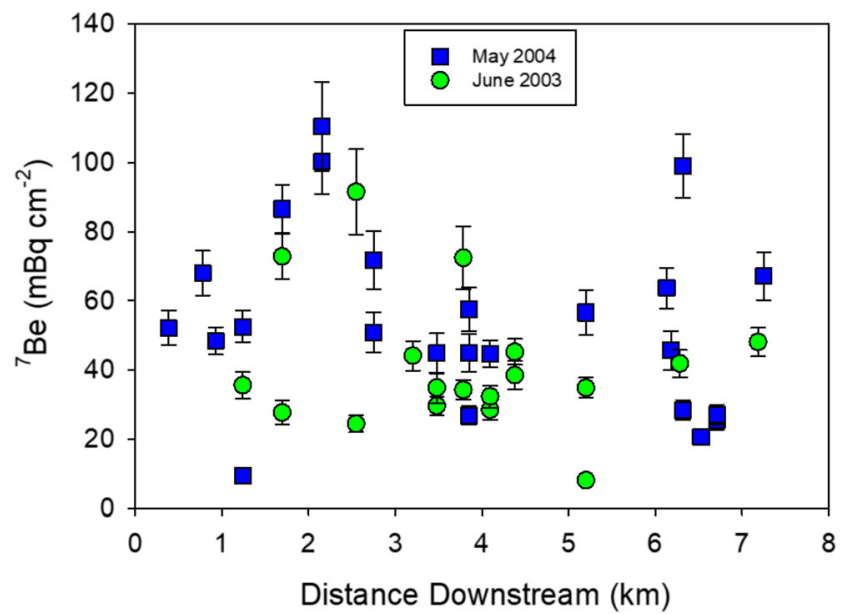

Fig. 2 Synoptic distribution of ${ }^{7} \mathrm{Be}$ in surficial sediments of the Branford River estuary. There is a large variation with distance downstream and sometimes in short distances across the river at a single distance downstream. Note also that variability is much greater than the measurement uncertainty. Distances are measured from the head of tides at the Ward's Millpond dam

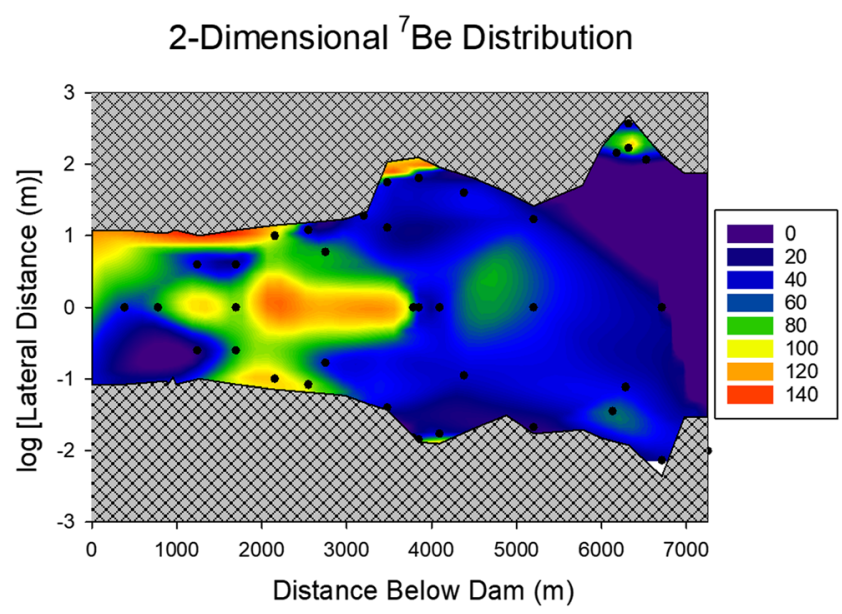

Fig. 3 Contour plot of ${ }^{7} \mathrm{Be}$ in surface sediments of the Branford River estuary. Adding the transverse dimension and combining both year's data, there is a suggestion of a down river decline in ${ }^{7} \mathrm{Be}$. Confirmation of this trend would require greater coverage in both space and time. The river has been straightened by plotting the log of the lateral width as a function of distance along the thalweg. Distance is measured from the dam on Ward's Millpond. Black dots represent sampling locations. Down is generally NW and up is SE. Contouring was carried out by Kriging within Sigmaplot 11.2, (92008 Systat Software. Units: $\mathrm{mBq} \mathrm{cm}^{-2}$

sample of estuarine water. However, for the final two samples of the second storm (November 18, 2002 21:00 and November 19, 2002 9:00), sample cores were not taken, only water. A similar sampling scheme was followed to monitor a storm in July 2004. The total atmospheric deposition of the storms was monitored based on simultaneous rooftop collections on the Environmental Science Center (21 Sachem St, New Haven, CT).

\section{Analytical Methods}

${ }^{7} \mathrm{Be}$ in water samples was concentrated by co-precipitation with $\mathrm{Fe}(\mathrm{OH})_{3}$ after $\mathrm{pH}$ adjustment and centrifugation (Olsen et al. 1986). Stable Be was added as a yield monitor and measured by ICP-AES. Recoveries exceeded $95 \%$ in all cases. Homogenized sediments for ${ }^{7} \mathrm{Be}$ were sealed in cans and

Table 1 Sampling times compared to local high tides and rain events

\begin{tabular}{llll}
\hline & High tide & Sample & $\begin{array}{l}\text { Difference } \\
(\mathrm{min})\end{array}$ \\
\hline November/16/2002 & \multicolumn{2}{l}{ Rain begins: 21:00 } \\
& $21: 55$ & $20: 52$ & -63 \\
November/17/2002 & $7: 50$ & $9: 06$ & +76 \\
& $22: 35$ & $21: 33$ & -62 \\
November/18/2002 & $8: 35$ & $9: 44$ & +69 \\
& Rain ends: 12:00 & \\
& $21: 00$ & $22: 13$ & +73 \\
November/19/2002 & $9: 00$ & $10: 21$ & +81 \\
\hline
\end{tabular}


measured wet with no further pretreatment, so activities are expressed normalized to area $\left(19.6 \mathrm{~cm}^{2}\right.$, that of the core liner used) rather than by weight. All samples were analyzed via gamma spectroscopy on a low-energy, low-background Canberra® gamma counter with planar geometry, correcting for self-absorption (Cutshall et al. 1983), which was minimal for ${ }^{7} \mathrm{Be}$ with its relatively high energy. $\mathrm{A}^{23} \mathrm{Na}$ standard was used for self-absorption tests because it has a similar gamma ray energy. Previously, counting efficiencies were determined for our system on the basis of the certified value for the ${ }^{7} \mathrm{Be}$ standard supplied by the manufacturer (NIDC). Because analyses were often delayed for several days, as measurement of individual samples can take $24 \mathrm{~h}$ or longer each, all ${ }^{7} \mathrm{Be}$ values were decay corrected to the time of collection via the standard radioactive decay equation.

\section{Results and Discussion}

\section{Atmospheric Deposition}

Because ${ }^{7} \mathrm{Be}$ that actually reaches the Earth's surface is produced mainly in the troposphere, the depositional flux is influenced by weather and location (Baskaran 1995; Renfro et al. 2013). ${ }^{7} \mathrm{Be}$ deposition tends to increase with latitude and with solar activity (Kaste et al. 2002). Most ${ }^{7} \mathrm{Be}$ is delivered to the Earth's surface with wet deposition, so the timing and magnitude of rainstorms has a strong influence on the amount deposited (Renfro et al. 2013). Total annual fluxes of ${ }^{7} \mathrm{Be}$ vary by as much as a factor of 7 from one location to another globally, and the amount delivered by individual storms at a single place can vary by at least a factor of 10 (Canuel et al. 1990). This means that most applications of ${ }^{7} \mathrm{Be}$ as a tracer require direct measurement of the local flux.

Based on 267 days of continuous monitoring and extrapolating to an average annual precipitation of $134 \mathrm{~cm}$ in Branford, CT, we estimate that annual ${ }^{7} \mathrm{Be}$ atmospheric deposition is $290 \mathrm{mBq} \mathrm{cm}^{-2}$ year $^{-1}$ or $0.79 \mathrm{mBq} \mathrm{cm}^{-2}$ day $^{-1}$. In order to estimate the total annual deposition, the ratio of average annual precipitation to precipitation-to-date was multiplied by the total amount of atmospheric deposition-to-date. It should be noted that this value was based on data that were collected over a 9-month period from October of 2002 to June of 2003. This was a period of near normal amounts of precipitation based on NOAA data from Tweed Airport, approximately $7 \mathrm{~km}$ from our study site. Because precipitation amount was typical, similar results are obtained whether extrapolation is based on time or rainfall. $\left({ }^{7} \mathrm{Be}\right.$ and rainfall amount were correlated at our site, with $P=0.033$.) This ${ }^{7} \mathrm{Be}$ input is adequate to maintain an inventory of $61 \mathrm{mBq} \mathrm{cm}^{-2}$ if the only loss is through radioactive decay. The average annual atmospheric deposition rate of ${ }^{7} \mathrm{Be}\left(290 \mathrm{mBq} \mathrm{cm}^{-2}\right.$ year $\left.^{-1}\right)$ we found is similar to published values for nearby Stony Brook, NY (311 mBq cm year $^{-1}$; Renfro et al. 2013).

\section{Spatial Variability in Estuarine Sediments}

Results reveal that there is great variability in ${ }^{7} \mathrm{Be}$ inventories along the length of the estuary and sometimes across it (Fig. 2). On each of the two sampling dates, the relative standard deviation for all measurements was $48 \%$. This indicates that scavenging and deposition of ${ }^{7} \mathrm{Be}$ is uneven in space or that surficial sediments are rapidly redistributed unevenly in the estuary. In either event, deposition and perhaps resuspension of tracer-tagged sediment appear to be complex. Grain size and chemical analysis were not performed, but all samples appeared to be similar muds. Similar or greater areal variability of ${ }^{7} \mathrm{Be}$ was found in the much larger, and geometrically simpler, basin of Lake Pontchartrain, LA (Flocks et al. 2009).

Information is also provided by depth distributions of ${ }^{7} \mathrm{Be}$ in sediments. In six cases, we sectioned cores at $0.5 \mathrm{~cm}$ intervals to evaluate ${ }^{7} \mathrm{Be}$. In all cases, no ${ }^{7} \mathrm{Be}$ was found deeper than $1.0 \mathrm{~cm}$. This both supports the validity of our sampling method (collecting the upper $5 \mathrm{~cm}$ of sediment) and suggests that vertical redistribution by biological or physical processes was limited on the timescale of ${ }^{7} \mathrm{Be}$ decay (i.e., months).

The two sets of surficial sediments we collected, totaling 42 samples, showed no simple pattern of ${ }^{7} \mathrm{Be}$ inventories either along the length of the estuary or between samples collected a year apart. Mean values were $54 \pm 26$ and $41 \pm$ $19.8 \mathrm{mBq} \mathrm{cm}^{-2}$ on the two dates, but results were not significantly different between the two dates. The data were not normally distributed, but a Mann-Whitney Rank Sum test revealed that the dissimilarity in the median values (51 and $35 \mathrm{mBq} \mathrm{cm}^{-2}$ year $^{-1}$ ) between the two groups is not great enough to exclude the possibility that the difference is due to random sampling variability, i.e., there is not a statistically significant difference between samples collected in the 2 years, using a $5 \%$ probability threshold $(p=0.082)$. Because of the short half-life of ${ }^{7} \mathrm{Be}$, less than $2 \%$ of the radionuclide measured on the first sampling date was still present on the second, so these are two completely independent measurements.

The two sets of samples collected nearly a year apart neither were significantly different nor were there simple systematic changes with only longitudinal distance in either set. Still, it should be pointed out that there are significant differences among individual samples even if there is not a clear longitudinal pattern to those variations. In other words, ${ }^{7} \mathrm{Be}$ is not simply homogenous within surficial sediments of the Branford River.

Because the 2 years' data were statistically the same, we combined them and added transverse distance as a variable (Fig. 3). The results begin to suggest a down river decline in ${ }^{7} \mathrm{Be}$ and perhaps a concentration near the margins, though 
even greater sample collection than was used in this study would be required to fully reveal the pattern.

Because of the variations we sometimes observed in samples taken only several tens of meters apart, we decided to evaluate spatial variability at even shorter scales. We collected two sets of triplicate surface sediments and one quadruplicate set (Fig. 4) from inside an area of roughly $1 \mathrm{~m}^{2}$ for each set, and the three groups were located within a few meters of each other. To minimize sampling artifacts, these samples were taken directly from the bottom in 5-cm-diameter core liners, without the intermediary of an Eckman dredge. These samples had a lower variability than did the entire estuary, but even these replicates showed considerable changeability (Fig. 4) on an apparently flat and featureless bottom (evaluated by direct visual observation). Taken together, the 10 samples had a standard deviation of $28 \%$. The results show that considerable variability exists even at this very small spatial scale.

One common cause of differences in metal levels in sediments is the amount of fines and/or iron or organic matter. We did not quantify these variables, but qualitatively, all samples at the intensively sampled site were similar fine muds; significant amounts of sand were absent, and color was invariant. Over this small area ( $\sim 10 \mathrm{~m}$ radius), where sediment characteristics were uniform, ${ }^{7} \mathrm{Be}$ inventories varied by $28 \%$. This suggests that at least this much variation can be explained by factors such as hydrodynamics and bioturbation rather than sediment composition. For the 42 samples, we collected throughout the rest of the estuary, variation in ${ }^{7} \mathrm{Be}$ inventories rises to $48 \%$. (Note that both of these numbers are large compared to our measurement uncertainty of 5-10\%.) A variation of even $48 \%$ (factor of 2 ) is small compared to the range of sedimentological variables documented to occur among different estuaries, where they can differ by orders of magnitude. Our own work on a similar small nearby estuary (Jordan Cove, CT; Benoit et al. 1999) and that of others (Barnegat

\section{Replicate Variability}

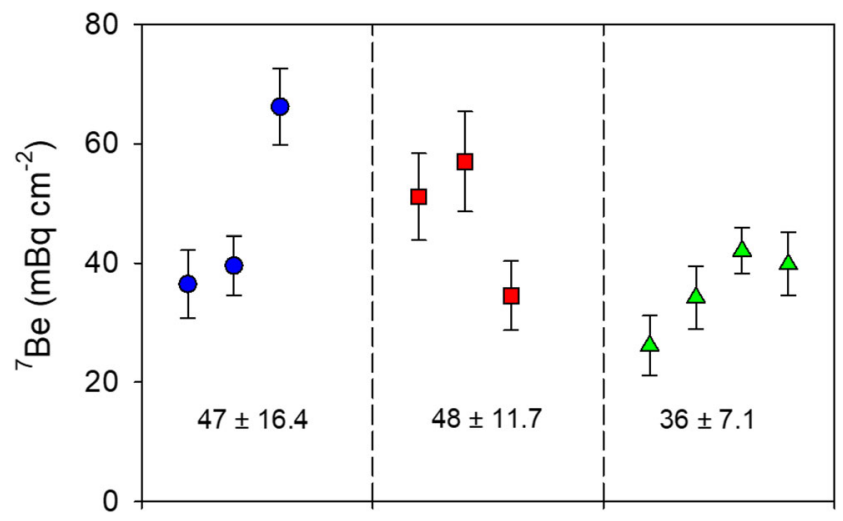

Fig. 4 Variability of ${ }^{7} \mathrm{Be}$ inventories for sets of replicates taken near each other between Indian Neck Ave and S Montowese St. Cores with symbols of a single shape were taken within $1 \mathrm{~m}$ of each other, and all three sets were taken less than $10 \mathrm{~m}$ apart
Bay, NJ; Taghon et al. 2017) suggest that sediment composition tends to vary only a small amount with location or depth. In contrast, for an estuary whose watershed is undergoing rapid change (Corsica $\mathrm{R}$ estuary, $\mathrm{MD}$ ), changes with depth can be great (Palinkas 2013). ${ }^{7} \mathrm{Be}$ throughout the estuary was not significantly different on the two sampling dates, but it was not identical within the measurement uncertainty (5-10\%) or the variation caused locally by physical factors ( $28 \%$ due to hydrodynamics or bioturbation). The remaining differences could be the result of sediment compositional differences, but the effect appears to be small in this estuary.

\section{${ }^{7}$ Be Cycling during Storm Events}

\section{The Water Column}

The third part of the research was to monitor ${ }^{7} \mathrm{Be}$ as it cycled through the Branford River watershed and estuary during storm events. ${ }^{7} \mathrm{Be}$ added to the estuary from the atmosphere and watershed is either already associated with particles or is quickly scavenged by them (Saari et al. 2010). Residence time of ${ }^{7} \mathrm{Be}$ in the water column of lakes and estuaries studied elsewhere usually falls in the range from 1 day to 2 weeks (Kaste and Baskaran 2011). This is the most complex part of the ${ }^{7} \mathrm{Be}$ cycle; the radionuclide is added directly to the estuary's surface or can flow in from the watershed. Thereafter, it is scavenged to bottom sediment or is removed by tidal flushing, and simultaneous resuspension is also possible. Understanding all of these processes requires measuring ${ }^{7} \mathrm{Be}$ in both estuarine water and sediment relatively frequently over time.

The results of the time-series sampling during the storms for the water column are shown in Figs.5, 6, and 7 along with discharge data available from the USGS for the adjacent Mill River in Hamden, Connecticut (USGS 01196620). These flow data were used because it is the nearest gauging station (instrument is $16 \mathrm{~km}$ distant), and the Mill River is similar to the Branford River in land use, size, soils, plant communities, level of development, topography, and other characteristics, and the weather experienced at both locations during the storm is likely to be very similar. This is especially true since the storm in November was of the frontal type, which varies little over broad areas.

The November storms had two distinct peaks roughly $24 \mathrm{~h}$ apart, as indicated by the discharge data and rainfall record (Fig. 5). Note that this bimodality applied to water flow, not necessarily ${ }^{7} \mathrm{Be}$ input, which is only approximately proportional to rainfall amount. Rain for these two storms contained $1.63 \mathrm{mBq} \mathrm{g}^{-1}$ (of water) and accumulated to a total depth of $4.1 \mathrm{~cm}$ (rainfall amount). Direct atmospheric deposition thus contributed $6.6 \mathrm{mBq} \mathrm{cm}{ }^{-2}$ of ${ }^{7} \mathrm{Be}$ to the surface of the estuary in these two storms. By comparison, based on the water column 
Fig. $5{ }^{7} \mathrm{Be}$ in the water column during two storms (filled circles). Rain amounts are vertical bars. Vertical lines represent times of high tides. NB: The small open circles are discharge for the nearby Mill River; they are not a fit to the ${ }^{7} \mathrm{Be}$ data. To facilitate comparison of water column and sediment data, water concentrations have been integrated over the average water depth of $2 \mathrm{~m}$
Storms 16 - 18 November 2002

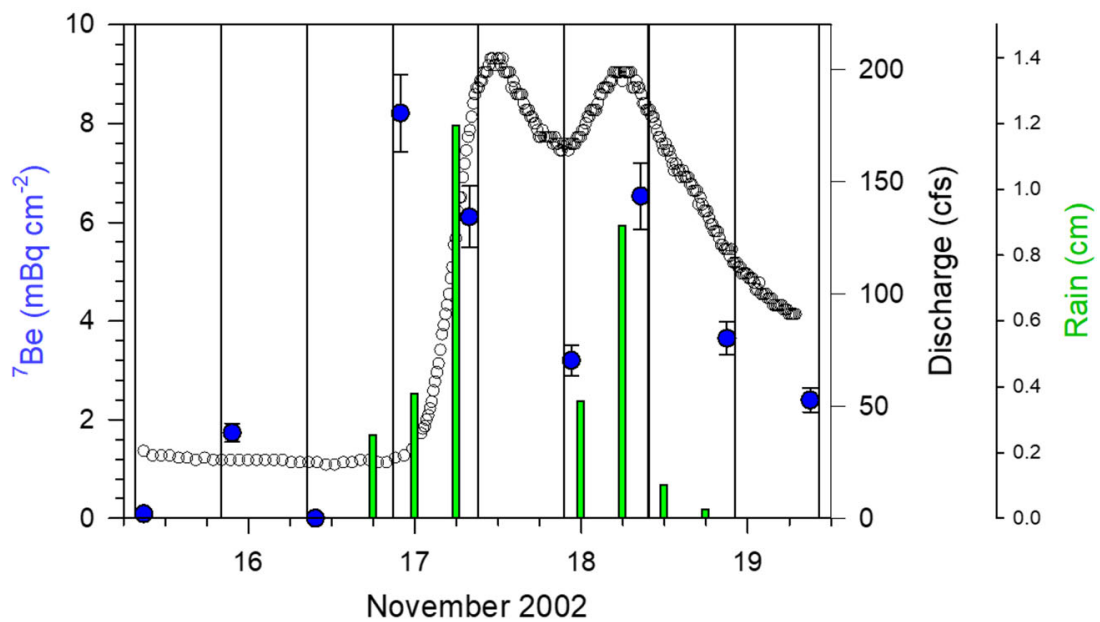

measurements, the two storms increased ${ }^{7} \mathrm{Be}$ in the estuary by 8.2 and $3.3 \mathrm{mBq} \mathrm{cm}^{-2}$ for a total of $11.5 \mathrm{mBq} \mathrm{cm}{ }^{-2}$, significantly greater than that coming directly from the atmosphere. This increase occurred even though both scavenging/sedimentation and tidal flushing should have decreased ${ }^{7} \mathrm{Be}$ inventories, so the net rise suggests that inflow from the watershed contributed a significant amount of the radionuclide. (On the timescale of the storm, radioactive decay of ${ }^{7} \mathrm{Be}$ is small.)
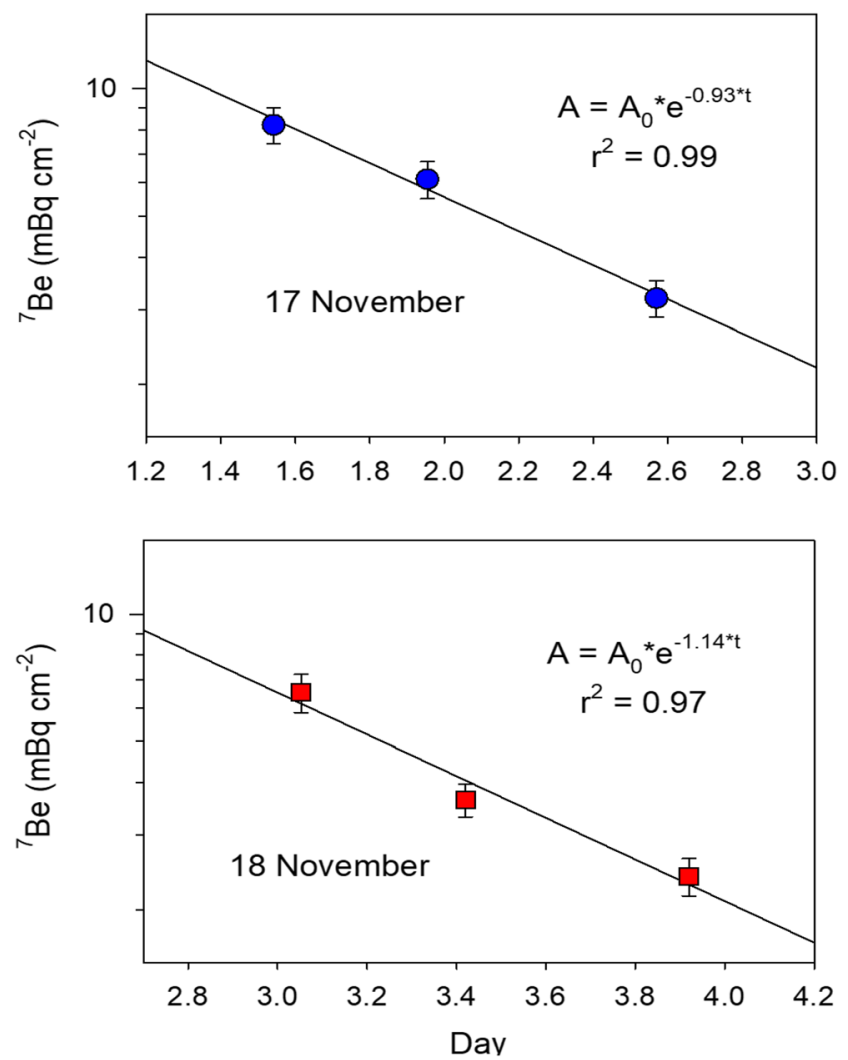

Fig. 6 Exponential loss of ${ }^{7} \mathrm{Be}$ from the water column for two November storms
The third storm showed a similar pattern (Fig. 7), with exponential decline in water column ${ }^{7} \mathrm{Be}$ over at least the first $48 \mathrm{~h}$. Adding inputs from precipitation and the watershed to ${ }^{7} \mathrm{Be}$ pre-existing in the water column produced a good match with exponential removal during and after the storm. Taken together, the three storms had e-fold $\left(\mathrm{e}^{-1}=0.37\right)$ removal rate constants of $1.00 \pm 0.12$ day $^{-1}$. Clearly, scavenging and sedimentation are rapid in this system. This removal reflects the combination of scavenging of any dissolved ${ }^{7} \mathrm{Be}$ and subsequent net sedimentation, as well as removal by other processes (like tidal flushing). It is worth noting that tidal flushing

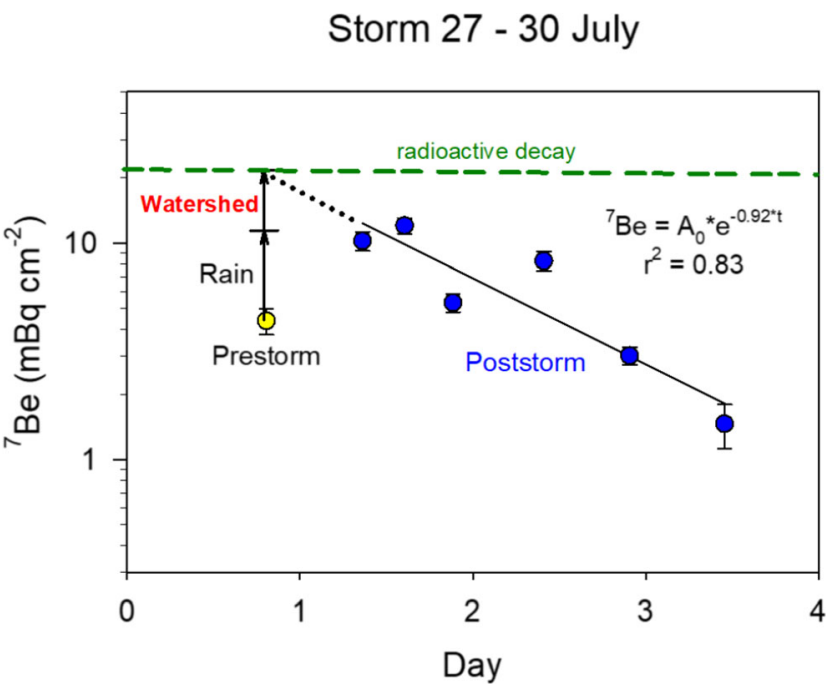

Fig. 7 Removal of ${ }^{7} \mathrm{Be}$ from the water column of the Branford River estuary during a storm in July 2004. The point labeled "Prestorm" is depth-integrated ${ }^{7} \mathrm{Be}$ in the water column before the start of rainfall. "Rain" is ${ }^{7} \mathrm{Be}$ measured in rainfall. "Watershed" is the product of radionuclide concentration $\left(\mathrm{Bq} \mathrm{m}^{-3}\right)$ and discharge $\left(\mathrm{m}^{3}\right.$ day $\left.{ }^{-1}\right)$ measured at the USGS gaging station on the Mill River scaled to the full drainage basin of the Branford River and normalized to estuary area $\left(\mathrm{cm}^{2}\right)$. The solid line is a regression of ${ }^{7} \mathrm{Be}$ measured in the water column; the inventory decreases much faster than the rate of radioactive decay (approximately $5 \%$ over 4 days), which is shown for comparison 
cannot be $100 \%$ efficient, or ${ }^{7} \mathrm{Be}$ might be expected to drop nearly to zero after a single tidal cycle ( $\sim 0.5$ day), as the tidal range in the Branford River estuary $(\approx 2 \mathrm{~m})$ is similar to the average water depth $(<3 \mathrm{~m})$. Considering the rapid rate of scavenging when ${ }^{7} \mathrm{Be}$ is high, the continued presence of measurable radionuclide in the water column between storms suggests that it is being restored by some process(es) when levels are lower. These might be resuspension of bottom sediments or exchange with Long Island Sound.

\section{${ }^{7}$ Be in Sediment Cores}

We also monitored ${ }^{7} \mathrm{Be}$ in sediments during the November storms, with the expectation of documenting accumulation of a pulse input that might be deposited to the bottom from radionuclide added via direct deposition or inflow from the watershed. The results were inconclusive. As the storm began, the total beryllium found in sediment samples was very low in the upper $5 \mathrm{~cm}$. (In fact, no ${ }^{7} \mathrm{Be}$ was measured in any sample below $1.0 \mathrm{~cm}$.) Then, near the start of the storm, a relatively large amount was detected at the surface $\left(37 \pm 2.3 \mathrm{mBq} \mathrm{g}^{-1}\right.$ between 0 and $0.5 \mathrm{~cm}$ deep; Fig. 8.) As the storm progressed, more ${ }^{7} \mathrm{Be}$ was delivered from the atmosphere $\left(6.6 \mathrm{mBq} \mathrm{cm}^{-2}\right)$ to the Branford River. The ${ }^{7} \mathrm{Be}$ rapidly adsorbed to particles, which were quickly removed from the water column by sedimentation. This is evident as the ${ }^{7} \mathrm{Be}$ activity in the sediments increased in a sample taken after the start of the storm $(49 \pm$ $2.8 \mathrm{mBq} \mathrm{g}^{-1}$ in the upper half-centimeter of sediment and 20 $\pm 1.8 \mathrm{mBq} \mathrm{g}^{-1}$ in the $0.5-1.0 \mathrm{~cm}$ sample). This suggests the

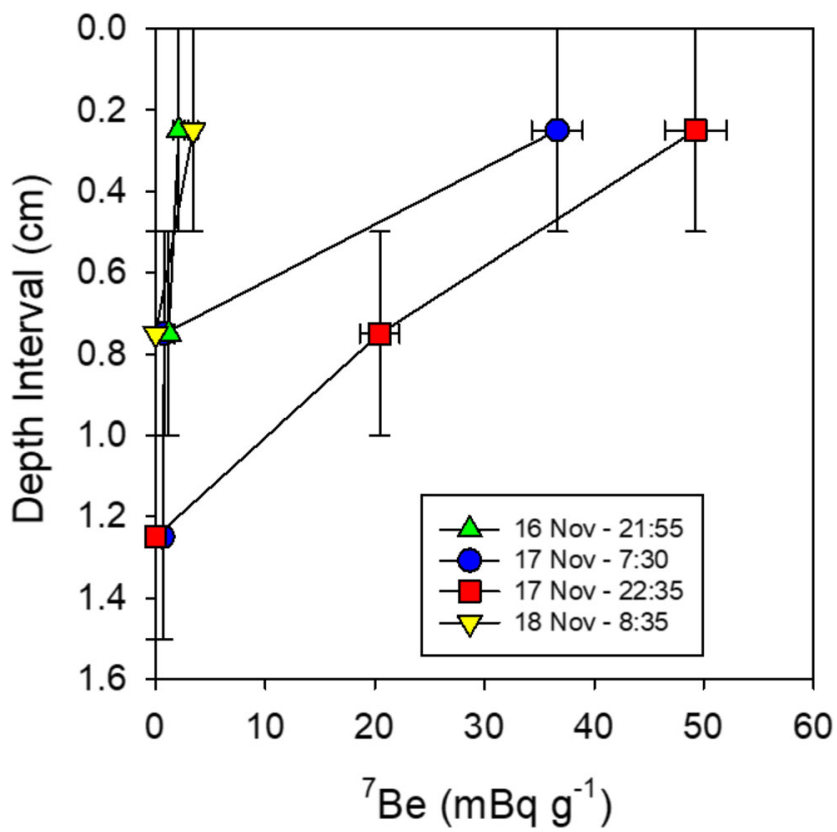

Fig. $8{ }^{7} \mathrm{Be}$ in surficial sediment cores during the November 2003 storm. Rainfall started near 18:00 on November 16. Horizontal bars are measurement uncertainty. Vertical bars reflect sampling depth intervals rather than uncertainties, which are less than $0.1 \mathrm{~cm}$. rapid removal of ${ }^{7} \mathrm{Be}$-rich sediment from the water column. But there was a rapid decrease in sedimentary ${ }^{7} \mathrm{Be}$ activity following the conclusion of the storm. The most likely explanation for this disappearance is that most of the ${ }^{7} \mathrm{Be}$ was resuspended and lost to other sediment locations. This is consistent with the lack of ${ }^{7} \mathrm{Be}$ at this location at the outset of the storm, suggesting that it is not a site of long-term sediment accumulation.

\section{Medium Term Water Column Cycling}

To better understand medium-term variability of ${ }^{7} \mathrm{Be}$ inventories in sediments, we collected surface samples repeatedly between rainstorms for a period of 3 months (Fig. 9). Within measurement uncertainty, sedimentary ${ }^{7} \mathrm{Be}$ could be explained by loss through radioactive decay and gain from deposition of atmospheric ${ }^{7} \mathrm{Be}$. Additional loss from bottom sediments, perhaps associated with high winds causing above normal sediment resuspension and export, may have occurred around day 36 of the sample series, but this apparent deficiency again may be the result of spatial variability of sediment inventories. The generally good prediction shown in Fig. 9 supports the idea that inventories in sediments reflect a balance between net deposition (rain/scavenging/settling minus any resuspension) and loss through decay.

\section{${ }^{7}$ Be Mass Balance for the Estuary}

All of our measurements can be integrated in a mass balance that compares relative magnitudes of various reservoirs and fluxes. In calculating a ${ }^{7} \mathrm{Be}$ mass balance for the entire estuary,

\section{${ }^{7}$ Be Time Series}

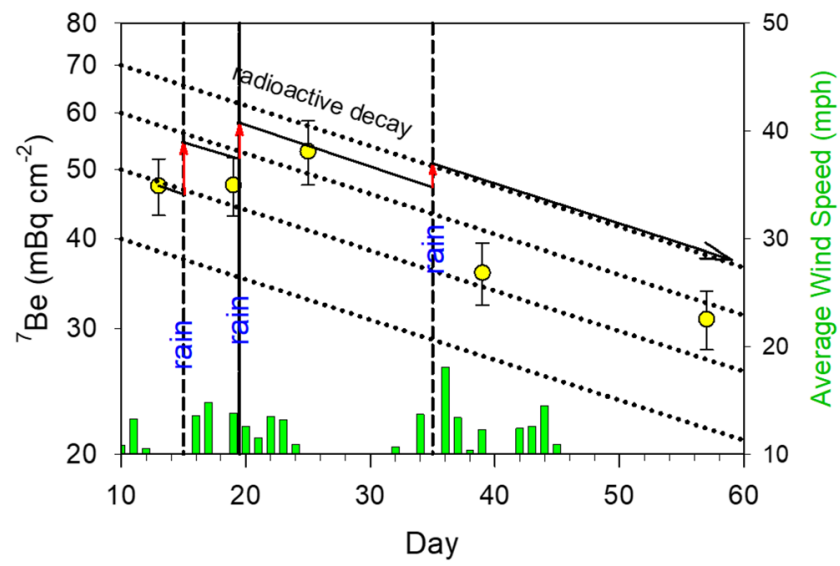

Fig. 9 Comparison of ${ }^{7} \mathrm{Be}$ inventory in bottom sediment to loss by radioactive decay and gain from atmospheric input. Slanting dotted lines parallel the rate of radioactive decay. Bars are average daily wind speeds (right axis). Rain events are marked by vertical dashed lines and corresponding vertical arrows are measured ${ }^{7} \mathrm{Be}$ inputs. Over the medium term, ${ }^{7} \mathrm{Be}$ in sediments seems to be nearly in steady state between these gain and loss terms 
it is important to keep in mind several concepts and numbers. First, most measurements are made on a small areal basis and need to be scaled up to the entire estuarine area. The conversion is that $1.0 \mathrm{mBq} \mathrm{cm}^{-2}$ translates to $9.1 \mathrm{MBq}$ over the entire estuarine surface. Second, the half-life of ${ }^{7} \mathrm{Be}$ is short, so significant changes caused by radioactive decay might occur on the time scale of ecosystem wide events (return time of storms, inflow from the watershed, and synodic tidal cycles). For these reasons, it is best to think of the mass balance normalized for a period shorter than the half-life (53 days) or mean life ( 77 days) of ${ }^{7} \mathrm{Be}$, and to realize the results can only be average values, as many processes are episodic rather than continuous. We chose to normalize results to a 1-day period, though other similar time steps would produce like results.

For the mass balance (Fig. 10), we directly measured inputs from the (A) Atmosphere and (B) Watershed and the standing stock in (C) Sediments. Measurement of (A) was based on many analyses over most of a year, whereas (B) was based on measurements on just three storms. The amount of ${ }^{7} \mathrm{Be}$ in reservoir (C) was based on a total of 53 measurements taken on two occasions nearly a year apart and showed relatively little variation between the two averages. From (C), it is easy and reliable to calculate loss via radioactive (D) Decay, and lacking other source or sink terms for Sediments, this must be equal to average net sediment (E) Deposition in the long term. (We use Deposition to mean net settling less any resuspension. The latter cannot be large or levels in the water column would need to be much greater than we measured.) The standing stock and decay loss in the (F) Estuary's water column was directly measured but is highly variable on short time scales (hours to days). Although the uncertainty is large, this term is small in the total budget. Finally, exchange with Long Island Sound $(G)$ is calculated by difference between sources (Watershed and Atmosphere) and sinks (net Deposition and water column decay). In this mass balance, we assume the

\section{Branford River ${ }^{7}$ Be Mass Balance}

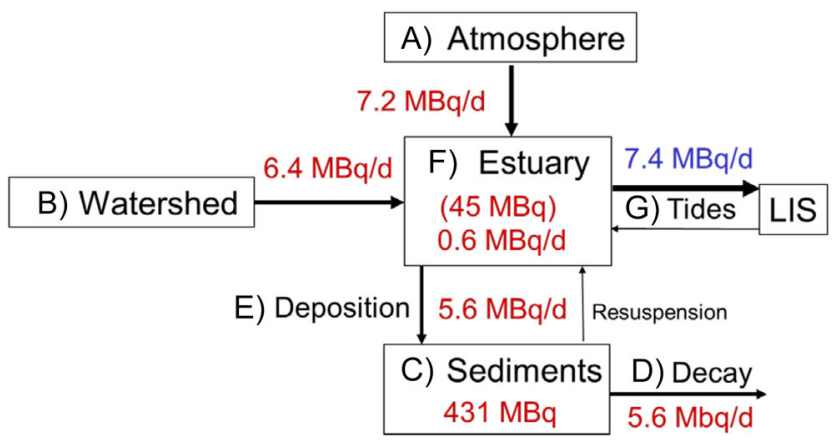

Fig. 10 Mass balance of ${ }^{7} \mathrm{Be}$ in the Branford River estuary normalized to a 1-day period. Boxes represent reservoirs, and arrows are fluxes. For $(\mathbf{F})$ Estuary, the upper number is the typical standing stock and the lower number is the decay loss. The $(\mathbf{G})$ Tides and (E) Deposition fluxes are net amounts, which include tidal inflow and resuspension, respectively, which were not measured independently, but are believed to be small amount of ${ }^{7} \mathrm{Be}$ in the water column $(\mathrm{F})$ is constant, which must be true, on average, over longer periods of time because there is no secular trend. But both $(\mathrm{F})$ and $(\mathrm{G})$ will fluctuate significantly depending on when it rains and which tidal cycle is measured. Because the tidal term was calculated by difference and not directly measured, it is impossible to test for closure of the mass balance. We have begun direct measurements of tidal flushing and ${ }^{7} \mathrm{Be}$ for the nearby West River to remedy this shortcoming (manuscript in preparation).

(A) Atmosphere The average atmospheric flux directly to the surface of the estuary was $7.2 \times 10^{6} \mathrm{~Bq} \mathrm{day}^{-1}$ $\left(7.2 \mathrm{MBq}\right.$ day $\left.^{-1}\right)$. As described earlier, this was based on 267 days of analyses and is very similar to other nearby measurements (Renfro et al. 2013).

(B) Watershed Upstream from the dam that forms Ward's Millpond, the watershed has an area of $57 \mathrm{~km}^{2}$, with an additional $6 \mathrm{~km}^{2}$ of watershed area between there and Long Island Sound. The estuary itself has a surface area of $0.91 \mathrm{~km}^{2}$. Based on measurements of ${ }^{7} \mathrm{Be}$ in Branford River water and USGS gauging data for the adjacent Mill River, we calculated a riverine flux of $6.4 \mathrm{MBq}$ day $^{-1}$ scaled to the entire watershed area. This relatively large contribution from the watershed (compared to other estuarine studies) probably reflects the large ratio of watershed to estuary areas $(69: 1)$. Still, the riverine flux represents only $1.4 \%$ of the ${ }^{7} \mathrm{Be}$ landing on the watershed, a small fraction consistent with previous findings elsewhere (Dibb and Rice 1989a; Olsen et al. 1986). The ${ }^{7} \mathrm{Be}$ that is transported by the river is a combination of direct deposition to the water's surface and erosion of soil particles that received atmospheric ${ }^{7} \mathrm{Be}$ in the past few months. Several investigators have used ${ }^{7} \mathrm{Be}$ as a tracer of eroded soils and have compared sources from different depths in the soil profile by using atmospherically deposited radionuclides of differing half-lives (Bonniwell et al. 1999; Matisoff et al. 2002; Wallbrink and Murray 1993; Wallbrink and Murray 1996).

The pond itself is very shallow $(\bar{z}<2 \mathrm{~m})$ and small (2 ha). Based on the size of the watershed, the volume of the pond, and typical runoff amount (50\%), water residence time in the pond for a $2-\mathrm{cm}$ storm lasting $12 \mathrm{~h}$ is less than $1 \mathrm{~h}$. We expect that it captures an insignificant portion of ${ }^{7} \mathrm{Be}$ delivered from the watershed, but have no data. Nevertheless, our measurements are from below the dam, so the pond's influence is taken into account in our analysis. Still, our result for delivery of ${ }^{7} \mathrm{Be}$ from the watershed downstream may be an underestimate if substantial amounts are trapped behind the dam.

(C) Sediment The total inventory in sediments during the period of the mass balance was $431 \mathrm{MBq}$. Radioactive 
decay of this standing stock of ${ }^{7} \mathrm{Be}$ over 1 day amounts to the "(D) Decay" flux in the mass balance. Coincidentally, this is close to the deposition flux from the atmosphere to the estuary's surface. One way this could occur would be if ${ }^{7} \mathrm{Be}$ supplied by precipitation were nearly quantitatively captured in sediments (no losses to Long Island Sound), and there were no other sources to the estuary. As explained earlier, the significant contribution from the watershed shows that this is not the case. Because decay must be matched by net deposition for the sediment inventory to remain constant in the long run, as has been documented by our measurements, average net (E) Deposition (i.e., deposition less resuspension loss) can be calculated to be $5.6 \mathrm{MBq}$ day $^{-1}$ based on the inventory in sediments and the ${ }^{7} \mathrm{Be}$ mean life.

(F) Estuary ${ }^{7} \mathrm{Be}$ levels in the water column before, during, and after the storm studied in July 2004 fell in the range from 10 to $84 \mathrm{MBq}$, with highest levels occurring towards the end of rainfall, and lower levels before and after. We use the calculated average of $45 \mathrm{MBq}$ for the standing stock, corresponding to a radioactive decay loss flux of $0.6 \mathrm{MBq}$ day $^{-1}$. (Particle settling is captured separately in term (E)). Although radioactive decay loss has a large relative uncertainty, it is a small number in the budget.

(G) Tides Direct measurement of the net ${ }^{7} \mathrm{Be}$ tidal flux would be extremely difficult because of the large variations with each cycle. By difference between inputs from rain and the watershed $\left(7.2+6.4 \mathrm{MBq} \mathrm{day}^{-1}\right)$ and loss to sediment deposition and decay in the water column $(5.6+$ $0.6 \mathrm{MBq}$ day $^{-1}$ ), the net exchange with Long Island Sound can be calculated as a loss of $7.4 \mathrm{MBq}$ day $^{-1}$ for an average 1-day period. The overall budget thus indicates roughly equal inputs from the atmosphere and the watershed, along with slightly greater loss to tidal flushing compared to deposition within the estuary; the estuary is a very leaky trap for ${ }^{7} \mathrm{Be}$ and probably other particlereactive substances as well.

Uncertainty Analysis We calculated uncertainties for each term in the mass balance (Table 2) in an effort to assess the error in our calculation of the tidal exchange term $(\mathrm{G})$. The measurement uncertainties for ${ }^{7} \mathrm{Be}$ are a function of the number of decays recorded (viz. (counts) ${ }^{-1 / 2}$ ) and were always less than the real natural variability of the terms being measured. On this basis, measurement errors were considered negligible and were disregarded in this analysis. Instead, we calculated the standard errors of the means and combined them in quadrature to apply to the calculated Tidal term, as is appropriate for independent random errors like those in this case (Taylor 1982). In doing this analysis, we combined precipitation data,
Table 2 Analysis of uncertainty for the ${ }^{7}$ Be mass balance. Standard errors of the mean were calculated for each term based on individual values and the total number of measurements. Numbers in parentheses reflect values derived directly from other measurements (e.g., E is a direct consequence of $\mathrm{C}$ ). The tidal exchange term was calculated by difference: $\mathrm{G}=\mathrm{A}+\mathrm{B}-\mathrm{E}-\mathrm{F}$, and its uncertainty was calculated as described in "Uncertainty Analysis". The two values in italics (term G) were derived by combination of the other terms as described in the text

\begin{tabular}{|c|c|c|c|c|}
\hline & \multirow[t]{2}{*}{ Number } & \multicolumn{2}{|l|}{ Value } & \multirow{2}{*}{$\begin{array}{l}\text { Uncertainly } \\
\text { (SEM) } \\
(\%)\end{array}$} \\
\hline & & $(\mathrm{MBq})$ & $\left(\mathrm{MBq}\right.$ day $\left.^{-1}\right)$ & \\
\hline \multicolumn{5}{|l|}{ Sources } \\
\hline $\begin{array}{l}\text { (A) Atmospheric } \\
\text { deposition }\end{array}$ & 8 & & 7.2 & 15 \\
\hline (B) Watershed & 10 & & 6.4 & 16 \\
\hline \multicolumn{5}{|l|}{ Sinks } \\
\hline (E) Net sedimentation & (53) & & 5.6 & (8) \\
\hline (G) Tides & - & & 7.4 & (21) \\
\hline $\begin{array}{l}\text { (F) Water column } \\
\text { decay }\end{array}$ & (16) & & 0.6 & (17) \\
\hline \multicolumn{5}{|l|}{ Reservoirs } \\
\hline $\begin{array}{l}\text { (F) Water column } \\
\text { inventory }\end{array}$ & 16 & 45 & & 17 \\
\hline Sediments & 53 & 431 & & 8 \\
\hline
\end{tabular}

aggregating short-term measurements we did during storm sampling. Thus, we went from 14 measurements with durations ranging from 1 to 43 days to 8 binned results with periods from 18 to 44 days. The results of the assessment suggest that the tidal term has an uncertainty of about $21 \%$ of the calculated average value.

Conclusion from the Mass Balance It may be possible to generalize from the Branford River estuary to similar systems elsewhere. If the watershed to estuary area is high, and timescales of important biogeochemical processes are not long compared to the ${ }^{7} \mathrm{Be}$ half-life (flushing rates, storm frequencies), then inflow from land may be an important term, unlike what has been observed for larger systems where these conditions do not hold. Water column concentrations are likely to change rapidly, and tidal flushing will only be important if the water residence time in the estuary is short. A second key finding is that particle-reactive contaminants (trace metals, hydrophobic organics) are likely to be captured only partially in such estuaries, and that a substantial fraction will be rapidly lost to tidal flushing.

\section{Conclusions}

- Roughly half of ${ }^{7} \mathrm{Be}$ enters the Branford estuary from its watershed and half via direct deposition from the atmosphere on its surface. 
- Roughly $40 \%$ of added ${ }^{7} \mathrm{Be}$ is deposited in sediments within the estuary and $60 \%$ is lost to Long Island Sound via tidal flushing.

- The average annual atmospheric deposition of ${ }^{7} \mathrm{Be}$ in New Haven, CT, is $290 \mathrm{mBq} \mathrm{cm}^{-2}$ year $^{-1}$.

- ${ }^{7} \mathrm{Be}$ is rapidly removed from the water column with a rate coefficient close to $1.0 \mathrm{day}^{-1}$ for all processes combined.

- The Branford River is a "leaky trap" for contaminants that behave like Be. It is probable that other particle-reactive substances - including toxic metals and hydrophobic organics (like PCBs and pesticides) - will be rapidly removed from the water column (within a day or two) and about $40 \%$ will be trapped in sediments. The remainder will be flushed into Long Island Sound.

- A large number of samples are needed to characterize the variability of a system even as small as the Branford River estuary, and this unevenness is true in terms of both space and time.

Acknowledgments We give thanks to all of those that helped out with this project in the field and lab, particularly Dr. Steve Mylon, Alexis de Kerchove de Denterghem, and Jeremiah Johnson, all of Yale University.

Funding Information This project was funded in part by the Connecticut Sea Grant Internship Program of the Yale Center for Coastal and Watershed Systems and a grant to GB by the Connecticut Sea Grant College Program.

\section{References}

Barbier, E.B., S.D. Hacker, C. Kennedy, E.W. Koch, A.C. Stier, and B.R. Silliman. 2011. The value of estuarine and coastal ecosystem services. Ecological Monographs 81: 169-193. https://doi.org/10. 1890/10-1510.1.

Baskaran, M. 1995. A search for the seasonal variability on the depositional fluxes of $\mathrm{Be}-7$ and $\mathrm{Pb}-210$. Journal of Geophysical Research-Atmospheres 100: 2833-2840. https:// doi.org/10.1029/94jd02824.

Baskaran, M., and P.H. Santschi. 1993. The role of particles and colliods in the transport of radionuclides in coastal environments of Texas. Marine Chemistry 43: 95-114.

Benoit, G., T.F. Rozan, P. Patton, and C. Arnold. 1999. Heavy metals and radionuclides trace sediment sources and accumulation rate in Jordan Cove, Connecticut. Estuaries 22: 65-80.

Bonniwell, E.C., G. Matisoff, and P.J. Whiting. 1999. Determining the times and distances of particle transit in a mountain stream using fallout radionuclides. Geomorphology 27: 75-92.

Canuel, E.A., C.S. Martens, and L.K. Benninger. 1990. Seasonal variations in $7 \mathrm{Be}$ activity in the sediments of Cape Lookout Bight, North Carolina. Geochimica et Cosmochimica Acta 54: 237-245.

Cutshall, N.H., I.L. Larsen, and C.R. Olsen. 1983. Direct analysis of lead-210 in sediment samples: self absorption corrections. Nuclear Instruments and Methods in Physics Research 206: 309-312.
Dibb, J.E., and D.L. Rice. 1989a. The geochemistry of beryllium-7 in Chesapeake Bay. Estuarine, Coastal and Shelf Science 28: 379-394.

Dibb, J.E., and D.L. Rice. 1989b. Temporal and spatial distribution of beryllium-7 in the sediments of Chesapeake Bay. Estuarine, Coastal and Shelf Science 28: 395-406.

Dominik, J., D. Burrus, and J.-P. Vernet. 1987. Transport of the environmental radionuclides in an alpine watershed. Earth and Planetary Science Letters 84: 165-180.

Dutkiewicz, V.A., and L. Husain. 1985. Stratospheric and tropospheric components of Be-7 in surface air. Journal of Geophysical Research-Atmospheres 90: 5783-5788.

Feng H, Cochran JK, Hirschberg DJ (1999) Th-234 and Be-7 as tracers for the transport and dynamics of suspended particles in a partially mixed estuary Geochimica et Cosmochimica Acta 63:2487-2505.

Fitzgerald, S.A., J.V. Klump, P.W. Swarzenski, R.A. Mackenzie, and K.D. Richards. 2001. Beryllium-7 as a tracer of short-term sediment deposition and resuspension in the Fox River, Wisconsin. Environmental Science and Technology 35 (2): 300-305.

Flocks, J., J. Kindinger, M. Marot, and C. Holmes. 2009. Sediment characterization and dynamics in Lake Pontchartrain, Louisiana. Journal of Coastal Research (54): 113-126. https://doi.org/10.2112/si54011.1.

Howarth, R.W., A. Sharpley, and D. Walker. 2002. Sources of nutrient pollution to coastal waters in the United States: implications for achieving coastal water quality goals. Estuaries 25: 656-676. https://doi.org/10.1007/bf02804898.

Jweda, J., M. Baskaran, E. van Hees, and L. Schweitzer. 2008. Short-lived radionuclides $(\mathrm{Be}-7$ and $\mathrm{Pb}-210)$ as tracers of particle dynamics in a river system in southeast Michigan. Limnology and Oceanography 53: 1934-1944. https://doi.org/ 10.4319/lo.2008.53.5.1934.

Kaste JM, Baskaran M (2011) Meteoric Be-7 and Be-10 as process tracers in the environment. Handbook of Environmental Isotope Geochemistry, Vols 1 and 2. doi:https://doi.org/10.1007/978-3642-10637-8 5

Kaste, J.M., S.A. Norton, and C.T. Hess. 2002. Environmental chemistry of beryllium-7. In Beryllium: mineralogy, petrology, and geochemistry, ed. E.S. Grew, vol. 50, 271-289. Reviews in Mineralogy and Geochemistry.

Kennish, M.J. 2002. Environmental threats and environmental future of estuaries. Environmental Conservation 29: 78-107. https://doi.org/ $10.1017 / \mathrm{s} 0376892902000061$.

Matisoff, G., E.C. Bonniwell, and P.J. Whiting. 2002. Soil erosion and sediment sources in an Ohio watershed using beryllium-7, cesium137, and lead-210. Journal of Environmental Quality 31: 54-61.

Olsen, C.R., I.L. Larsen, P.D. Lowry, N.H. Cutshall, and M.M. Nichols. 1986. Geochemistry and deposition of Be-7 in riverestuarine and coastal waters. Journal of Geophysical Research, Oceans 91: 896-908.

Palinkas, C.M. 2013. Seasonal and interannual patterns of sedimentation in the Corsica River (MD): evaluating the potential influence of watershed restoration. Estuarine, Coastal and Shelf Science 127: 37-45. https://doi.org/10.1016/j.ecss.2013.04.015.

Renfro, A.A., J.K. Cochran, and B.A. Colle. 2013. Atmospheric fluxes of $\mathrm{Be}-7$ and $\mathrm{Pb}-210$ on monthly time-scales and during rainfall events at Stony Brook, New York (USA). Journal of Environmental Radioactivity 116: 114-123. https://doi.org/10.1016/j.jenvrad. 2012.09.007.

Roman, C.T., N. Jaworski, F.T. Short, S. Findlay, and R.S. Warren. 2000. Estuaries of the northeastern United States: habitat and land use signatures. Estuaries 23: 743-764. https://doi.org/10.2307/ 1352997.

Rozan, T.F., and G. Benoit. 2001. Mass balance of heavy metals in New Haven Harbor, Connecticut: the predominance of nonpoint sources. Limnology and Oceanography 46: 2032-2049. 
Saari, H.K., S. Schmidt, P. Castaing, G. Blanc, B. Sautour, O. Masson, and J.K. Cochran. 2010. The particulate $\mathrm{Be}-7 / \mathrm{Pb}$ $210(\mathrm{xs})$ and $\mathrm{Th}-234 / \mathrm{Pb}-210(\mathrm{xs})$ activity ratios as tracers for tidal-to-seasonal particle dynamics in the Gironde estuary (France): implications for the budget of particle-associated contaminants. Science of the Total Environment 408: 4784-4794. https://doi.org/10.1016/j.scitotenv.2010.07.017.

Taghon, G.L., P.A. Ramey, C.M. Fuller, R.F. Petrecca, J.P. Grassle, and T.J. Belton. 2017. Benthic invertebrate community composition and sediment properties in Barnegat Bay, New Jersey, 1965-2014. Journal of Coastal Research: 169-183. https://doi.org/10.2112/si78-013.1.
Taylor, J.R. 1982. An introduction to error analysis. Sausalito: University Science Books.

Vernberg, F.J. 1993. Salt-marsh processes - a review. Environmental Toxicology and Chemistry 12: 2167-2195. https://doi.org/10.1897/ 1552-8618(1993)12[2167:spar]2.0.co;2.

Wallbrink, P.J., and A.S. Murray. 1993. Use of fallout radionuclides as indicators of erosion processes. Hydrological Processes 7: 297-304.

Wallbrink, P.J., and A.S. Murray. 1996. Distribution and variability of Be-7 in soils under different surface cover conditions and its potential for describing soil redistribution processes. Water Resources Research 32: 467-476. 